\title{
Comparative Dose of Intracarotid Autologous Bone Marrow Mononuclear Therapy in Chronic Ischemic Stroke in Rats
}

\author{
Feda Makkiyah $^{1 *}$, Wismaji Sadewo ${ }^{2}$, Rahmah Hida Nurrizka ${ }^{3}$ \\ ${ }^{1}$ Department of Neurosurgery, Faculty of Medicine, UPN Veteran Jakarta, Depok, Indonesia; ${ }^{2}$ Department of Neurosurgery, \\ Faculty of Medicine, Universitas Indonesia, Cipto Mangunkusumo Hospital, Central Jakarta, Indonesia; ${ }^{3}$ Department of Public \\ Health, Universitas Islam Negeri Syarif Hidayatullah Jakarta, South Tangerang, Indonesia
}

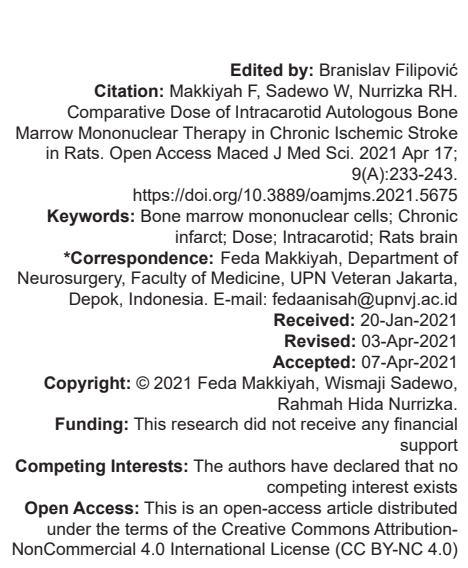

\section{Introduction}

Ischemic stroke represents a major cause of death and is the most prominent cause of permanent disability in adulthood. The chronic phase, where disabilities reach a plateau, has no known effective treatment regime and it is this fact which drives the search for novel therapeutic options for ischemic stroke treatment.

Cell therapies, in particular the use of bonemarrow-derived cell populations, are among the most promising approaches. Studies to date have shown that bone marrow mononuclear cell (BM-MNC) reduces infarct volume [1], decreases the thickness of glial scar, and enhances proliferation of oligodendrocyte precursors along the subventricular zone in the ipsilateral hemisphere [2]. During the chronic phase of stroke, it is hypothesized that the formation of new vessels by angiogenesis contributes to brain plasticity and functional recovery after stroke. Angiogenesis induces neurogenesis and vice versa.

A challenge in translational research to humans is the fact that the rodent is a totally different animal from humans. One of the main obstacles in the treatment of stroke is that the mechanism of recovery in chronic stroke ischemia is not yet fully understood and that the effective optimum dose has not yet been established. To better understand the possible mechanism underlying the effect of BM-MNC on chronic stroke ischemia, we measured the infarct zone, degree of angiogenesis, and neurogenesis at two different time periods and with two different dose levels. 


\section{Materials and Methods}

\section{Animals and experimental groups}

Thirty-two male Sprague-Dawley rats sourced from the Kalbe Farma Institution (Bandung, Indonesia), aged $6-10$ aged months, weighing $350-450 \mathrm{~g}$ were used in this study. The animals were assigned randomly to the following experimental groups (Figure 1a): (1) sham ischemic, necropsied at 8 weeks (control week $\left.8^{\text {th }}\right)(n=5)$; (2) sham ischemic, necropsied at 12 weeks (control week $\left.12^{\text {th }}\right)(n=5)$; (3) BM-MNCdose 5 million ischemic, necropsied at 8 weeks (Dose 5 Million week $\left.8^{\text {th }}\right)(n=5)$; (4) BM-MNC-dose of 5 million ischemic, necropsied at 12 weeks (Dose 5 Million week $\left.12^{\text {th }}\right)(n=5)$; (5) BM-MNC-dose 10 million ischemic, necropsied at 8 weeks (Dose 10 Million week $\left.8^{\text {th }}\right)(n=5)$; (6) BM-MNC-dose 10 million ischemic, and necropsied at 12 weeks $(n=5)$ (Dose 10 Million week $12^{\text {th }}$ ) (Figure 1). The rats were maintained in accordance with the guidelines of the NIH (Guide for the Care and Use of Laboratory Animals, 1976). All protocols were approved by the Animal Care and Use Committee of the Faculty of the University of Indonesia. All rats were given free access to food and water throughout the study.

\section{Temporary middle cerebral artery occlusion (MCAO) procedure}

After a week's adaptation in the Animal Research Facilities of the Faculty of the University of Indonesia, 32 rats underwent surgery by two experienced neurosurgeons trained in MCAO techniques. The following surgical procedures, originally described by Koizumi and Longa [3], [4] were used, being modified to have no coagulation and no clips being applied [5]. Body weight, heart rate, and respiration rate were measured before the procedure. The rats were anesthetized with ketamine xylazine (Xyla, Holland) $0.3-0.4 \mathrm{ml}$ in a $1 \mathrm{ml}$ syringe. Rectal temperature was maintained at $37 \pm 0.5^{\circ} \mathrm{C}$ throughout the surgical procedure. An incision was made in the midline of the neck. Then, the left common carotid artery (CCA), external carotid artery (ECA), and internal carotid artery (ICA) were isolated through a midline incision. Temporary knots were made in the left ECA, CCA, and ICA and two further temporary knots were then made in the ICA. Between these two knots, a small arteriotomy was made using a $26 \mathrm{G}$ needle. The subsequent steps were to insert a 4.0 proximal end heat blunted end of nylon monofilament (Ethicon, $\mathrm{NJ}$, USA) into the ICA until mild resistance was felt. Ninety minutes after occlusion, the nylon was withdrawn and the skin was sutured. One hour after the procedure was completed, neurological assessments were made using a 6 point neurological scale: (0) Means no deficits (1) difficulty in extending front extremities - indicating mild deficit. (2) circular movement in the direction of the paretic limb - indicating moderate deficit, (3) fall to the left - indicating severe deficit, (4) unable to walk indicating a decrease in consciousness, and (5) death due to severe brain ischemia [4]. All animals showed a circular movement favoring the paretic limb. To alleviate any pain, $24 \mathrm{~h}$ before the procedure and $24 \mathrm{~h}$ after the procedure, rats were given paracetamol syrup in their drinking water (paracetamol syrup, Soho) 1-2 mg/cc. The skin wound in the neck was given antibiotic skin ointment (Gentamicin sulfate $0.1 \%$, Kalbe). Two animals that appeared to be less active and hunched were excluded from the study. A postmortem autopsy showed subarachnoid hemorrhage in both rats.

\section{Harvesting procedure}

After 4 weeks (equivalent to the chronic phase of stroke in humans), 30 male Sprague Dawley rats were anesthetized by the method described above. No intubation was performed during the procedure. The anterior right knee joint was shaved and the area was disinfected with alcohol. The right knee joint was chosen as the isolation site because it was the paretic side. The bone marrow isolation was performed by the technique described by Ordodi et al. [6]. Before needle insertion, the right knee joint was moved into a flexion-extension position to facilitate access to the upper part of the joint - the preferred point of entry to the femur.

Using a 14 G needle of iv Catheter (SR-OX1451CA, Terumo, USA), the skin and muscle were pierced until the needle touched the bone. It was then carefully twisted until it was felt to be in the middle of the femur (diaphysis of the femur). The needle was attached to a $1 \mathrm{cc}$ syringe and inserted until it reached 1 $\mathrm{cm}$ before the hip joint. The needle was then removed and a new needle attached to the syringe to mitigate the risk that the previous needle might contain bone chips after bone drilling. To prevent the coagulation of the diaphysis content, the syringe was flushed with a $0.1 \mathrm{cc}$ EDTA solution (60-00-4, Sigma Aldrich, USA). Bone marrow $(0.5-1 \mathrm{ml})$ was aspirated while rotating and moving the needle back and forth. The medullary cavity was flushed with saline, and the content aspirated. The skin was cleaned with alcohol.

\section{Isolation of bone marrow}

Bone marrow that was isolated from the rat's femur was diluted 1:1 with phosphate-buffered saline (PBS). This suspension was placed on top of a ficollhypaque solution (1:1 comparison) in a glass tube and centrifuged for $10 \mathrm{~min}$ at $650 \mathrm{G}$ at $22^{\circ} \mathrm{C}$ with no brake. The mononuclear cell band was extracted with a pipette and washed immediately. This was centrifuged again for $10 \mathrm{~min}$ at $400 \mathrm{G}$ with brake at $22^{\circ} \mathrm{C}$. The supernatant was then discarded and the collected 


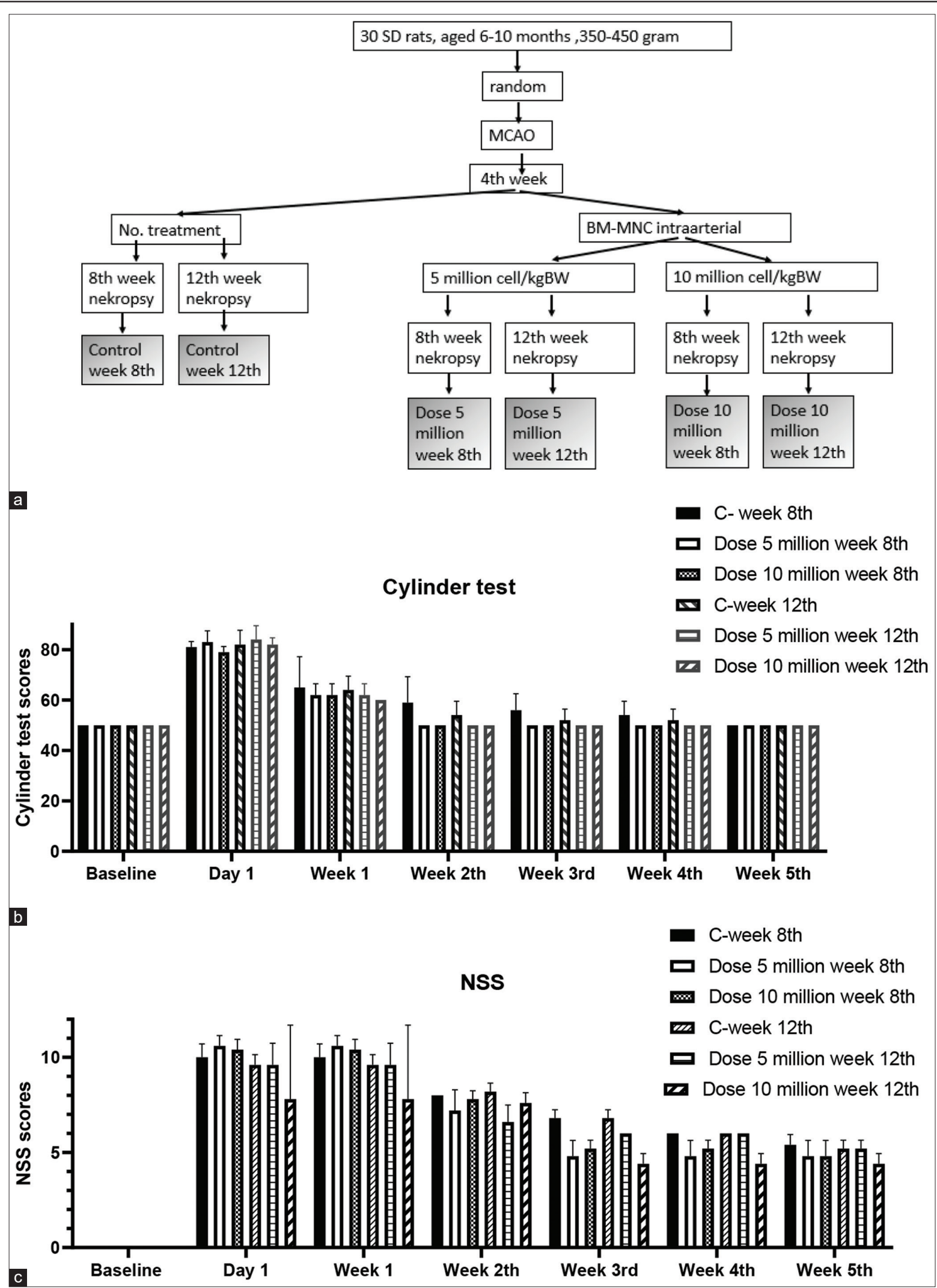

Figure 1: (a) Schematic representation of the experimental design. The study (30 rats in total) included the following groups (@ 5 rats): Sham ischemic necropsied 8 weeks ((Control week $\left.8^{\text {th }}\right)$, Sham ischemic necropsied 12 weeks (Control week12 $2^{\text {th }}$ ), bone marrow mononuclear cell $(B M-M N C)$ dose 5 million necropsied 8 weeks (Dose 5 million week $8^{\text {th }}$ ), BM-MNC dose 5 million necropsied 12 week (Dose 5 million week $12^{\text {th }}$ ), BM-MNC dose 10 million necropsied 8 weeks (Dose 5 million week $8^{\text {th }}$ ), BM-MNC dose 10 million necropsied 12 weeks (Dose 10 million week $12^{\text {th }}$ ). (b) Cylinder test scores on day 1 , week $1^{\text {st }}$ until week $5^{\text {th }}$. Cylinder test scores improved prior to the administration of BM-MNCs. (c) Neurological severity score (NSS) scores on day 1, week $1^{\text {st }}$ until week $5^{\text {th }}$. One-way ANOVA showed significant differences in week $3^{\text {rd }}$ and week $4^{\text {th }}$ in NSS scores $(p=0.005$ and $p=0.0034)$. NSS scores at week $4^{\text {th }}$ were markedly different between groups. Rats in group Dose 10 million week $12^{\text {th }}$ showed the lowest score (mean score 4). However, rats in the group of control week $8^{\text {th }}$, control week $12^{\text {th }}$, and Dose 5 million week $12^{\text {th }}$ had a mean score of 6 . Because of potential bias due to variation of the NSS score and cylinder test results in the week $4^{\text {th }}$ before BM-MNC administration in the sixth groups, both tests were not valid to evaluate the improvement of neurological function 
cellular pellet was placed in a solution of $1 \times$ PBS with a total volume of about $1 \mathrm{cc}$ [7], $10 \mu \mathrm{l}$ were collected for cell counting, and $200 \mu$ l were taken for analysis by the flow cytometer. Using flow cytometry BD FACS ARIA III, these cells were characterized and identified for the cluster of differentiation (CD)-34+ markers. The overall procedure took $3 \mathrm{~h}$ to complete.

\section{Intracarotid mononuclear cells injection}

Before receiving the injection, the rats were sedated with the same anesthetic formula as the MCAO procedure, followed by an incision in the middle of the neck, exposure to CCA, ICA, and ECA. Then, a temporary ligation was applied with a double loop of silk in CCA and ECA to reduce the blood flow to the injection site. A second double loop of silk was applied to the CCA. The site of arteriotomy was between the two loops of CCA. Polyethylene PE 50 (SIMS Portex Ltd ID: $0.635 \mathrm{~mm}$; OD: $1.19 \mathrm{~mm}$ ) was inserted through the arteriotomy site. $1 \mathrm{cc}$ mononuclear cell in saline solution was infused slowly (velocity about $1 \mathrm{cc} / \mathrm{min}$ ). The catheter was flushed with the saline solution. The catheter was released and the skin was closed with a nylon suture.

\section{Scale Score (NSS) \\ Cylinder tests and Neurological Severity}

The rats were assessed weekly using the cylinder test and behavioral observations to produce their NSS score.

The cylinder test provided a measure of rat's spontaneous forelimb use. Each animal was placed in a transparent plexiglass container and observed by independent researchers who recorded the number of independent wall placements for the right forelimb, left forelimb, and both forelimbs simultaneously for $10 \mathrm{~min}$. Each 10 min observation period required up to a total of twenty movements to be classified and recorded.

The modified NSS, commonly used in animal studies of stroke, uses ratings of neurological functioning on a scale from 1 to 18 , to obtain a composite score of the motor (muscle status and abnormal movement), sensory (visual, tactile, and proprioceptive), reflex, and balance tests. One point is given for the inability to perform each test and one point is deducted for the lack of a tested reflex, with the overall composite score indicating the degree of impairment.

\section{Necropsy procedure}

All animals survived the procedure and remained live until the time for a necropsy. After 4 weeks or 8 weeks of administration of intracarotid autologous mononuclear cells (week 8 and week 12 of the experiment), the rats were sacrificed. The brain was collected through the perfusion method using saline and normal buffer formalin until the tissue lost color. For histological studies, two consecutive 2-mm slices were analyzed from the level of MCAO (central part of the lesion) and $2 \mathrm{~mm}$ distal to the first slice.

\section{Infarct analysis}

The $\mathrm{H}$ and $\mathrm{E}$ slides were macrophotographed using a microscope and a Canon camera. Healthy tissue and border tissue between infarcted areas were outlined using software J (Image J; National Institutes of Health, Bethesda, MD). The infarct zone was determined by reducing the contralateral brain to the normal area of the ipsilateral zone.

\section{Immunohistochemistry}

Two biomarkers were used in this research: CD31 as a marker of angiogenesis and doublecortin as a marker of neurogenesis. The extent of angiogenesis was assessed from two consecutive 2-mm slices taken from the central part of the lesion and distal area for analysis. The brain slices were embedded in paraffin and brain microvessels evaluated by immunohistochemistry using a rat anti-CD31, Abcam [EPR17259] (ab182981). The second antibody was Goat Anti-Rabbit IgG H\&L (HRP). Five random areas around the focal cerebral infarction were imaged at 200x and the number of CD31 positive vessels was counted. A single endothelial cell separating from adjacent microvessels was considered to be the criterion for evidence of CD 31 positive vessels [8], [9].

The extent of neurogenesis was evaluated by immunohistochemistry using doublecortin (DCX), Abcam (EPR 19997 ab 207175). The second antibody applied was Goat Anti-Rabbit IgG H\&L (HRP). Five random areas in the subventricular zone were imaged at $400 \times$. Image $J$ was used to count the number of doublecortin positive cells.

\section{Statistics}

STATA 15 statistical software was used to analyze all data. All data distributed normally. Cylinder test scores and NSS scores were analyzed by one-way ANOVA repeated measures and post hoc Bonferroni. The size of the infarct zone, the CD 31 vessels, and the DCX-neuroblast were analyzed using one-way ANOVA and a post hoc Bonferroni test. To investigate the degree of correlation between time and dose, two-way ANOVA and simple mass effect analyses were conducted. A linear regression test was used to evaluate the correlation between CD34 and other variables. All data were displayed using Graph prism software as mean and \pm SD. The asterisk symbol $\left(^{*}\right)$ indicates a statistically significant difference. $p<0.05$ and $p<0.01$ were considered significant. 


\section{Results}

\section{Isolation and characterization of BM-MNC}

The range of BM-MNC per $\mathrm{ml}$ taken from ten samples was 2.5 million to 13 million and the presence of CD34+ cells was calculated to be from zero to $19.6 \%$. All rats survived the bone marrow isolation procedure and were able to stand and walk the next day.

\section{Cylinder test and neurological severity score assessment}

The cylinder test was used to assess the forelimb in MCAO rats. Before the procedure, all animals showed equal forelimb use. Following the MCAO procedure, there was a decrease in the use of the impaired forelimb (contralateral to the lesion) and an increase in the use of the unimpaired forelimb. After 4 weeks, all animals exhibited equal use of both the impaired and unimpaired forelimbs similar to their behavior before the procedure. For this reason, the cylinder test is considered to be unsuitable as a method for evaluating the long-term outcome of BM-MNC treatment.

The NSS scores of all rats before undergoing the MCAO procedure showed no neurological deficits. Following the MCAO procedure, the rats began to show moderate neurological deficits which persisted until the week before BM-MNC administration commenced (Figure 1b). Four weeks after the MCAO procedure, NSS scores between groups were markedly different.

Given the potential for statistical bias, both behavioral tests were excluded from statistical analysis. However, unlike the cylinder test, the comparison of NSS was considered appropriate for the evaluation of change in neurological deficit in the chronic phase of stroke ischemia.

\section{BM-MNCs treatment significantly reduced the infarct zone}

Three analyses yielded significant results. Compared with the saline group, the BM-MNCs treatment rats showed a significant reduction in lesion size $(p<0.01)$. The Bonferroni post hoc test demonstrated that the size of dose had a significant effect - 10 million cells per $\mathrm{kg} \mathrm{BW}$ significantly reduced lesion size compared with a dose of 5 million cells per $\mathrm{kg} \mathrm{BW}$. This was noted both at week $8^{\text {th }}$ and week $12^{\text {th }}$. The two-way analysis using ANOVA showed a significant interaction of dose size and period (weeks) in the reduction of lesion size $(p<0.01)$. A simple main effect test was used to assess the significance of the interaction of dose and period (weeks) and found that increasing the dose from 5 million cells to 10 million cells per $\mathrm{kg}$ BW had a greater effect size (2.67) at week $12^{\text {th }}$ than at week $8^{\text {th }}(95 \%$ Confidence Interval $-3.732991-$ 1.607009 , standard error 0.5150405).

\section{week 12}

Reduction of infarction size from week 8 to

There was no reduction in infarction size for the control group. However, the BM-MNCs treatment group showed a reduction in the size of infarction between week $8^{\text {th }}$ and week $12^{\text {th }}$. The differences in reduction of infarction size were observed in both high and low dose groups $(16.58 \pm 0.56,15.24 \pm 0.70$ vs. $19.74 \pm 0.92$ $18.41 \pm 0.20, p=0.019$ ) (Figure $2 a$ ).

\section{BM-MNCs treatment did not significantly improve angiogenesis in chronic stroke}

The rats in the BM-MNCs treatment groups showed a non-significant increase in the number of peri-infarction vessels in chronic stroke compared with the control group ( $p=0.1590$ ) (Figure $2 b)$. The number of CD31 positive cells, as a marker of angiogenesis, increased after BM-MNCs administration compared with the saline administration and a higher dose of BM-MNCs increased angiogenesis more than a lower dose of BM-MNCs; however, these differences were also not significant. Analysis of the interaction between dose and time (week) did not yield significant results $(p=0.3211)$.

\section{to week 12 \\ Improvement in angiogenesis from week 8}

The longer period of infarct increased angiogenesis in the BM-MNC groups. Even though a high dose increased the number of CD31 vessels more than was seen in the low dose groups, the difference was not statistically significant. There was no improvement in angiogenesis in the control groups at week $12^{\text {th }}$.

\section{BM-MNCs treatment significantly improved neurogenesis in chronic stroke}

BM-MNCs treatment enhanced neurogenesis significantly $(p<0.01)$ (Figure $2 c)$. The post hoc Bonferroni test showed a significant difference between the control group necropsied at week $8^{\text {th }}$ and the BM-MNCs dose 5 million per $\mathrm{kg} \mathrm{BW}$ necropsied at week $8^{\text {th }}(p<0.01)$.

A significant difference in neurogenesis was also seen between the control group necropsied at week $8^{\text {th }}$ and the BM-MNCs dose 10 million per $\mathrm{kg} \mathrm{BW}$ necropsied at week $8^{\text {th }}(p<0.01)$. Both the high and low doses of BM-MNCs enhanced neurogenesis at a similar level at week $8^{\text {th }}$. A similar difference was shown for the rats necropsied at week $12^{\text {th }}$. 


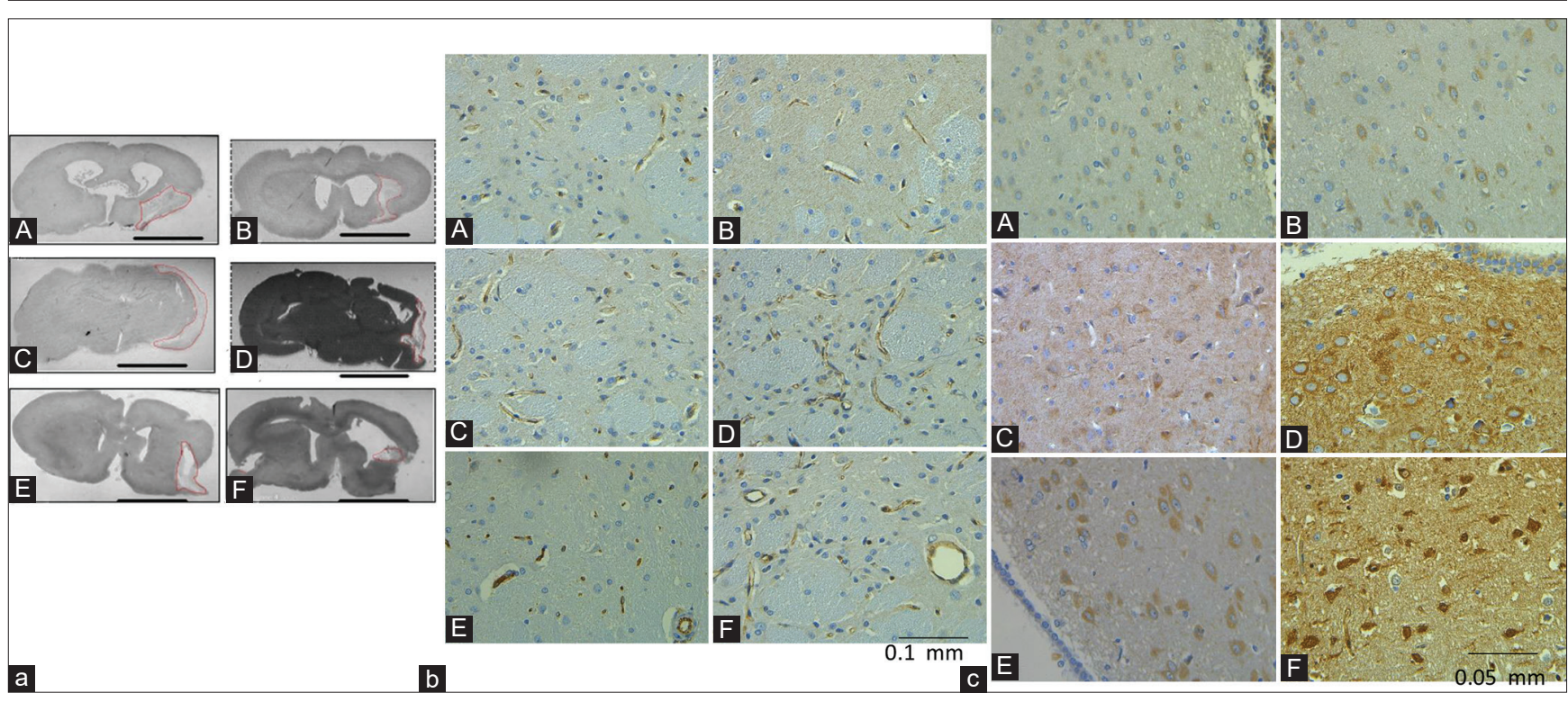

Figure 2: (a) Representative HE stained images showing the brain infarction in each brain section at different weeks after stroke and bone marrow mononuclear cell treatment. There was a reduction in infarction size from 8 to 12 weeks. A and $B$ Photomacrography of control week $8^{\text {th }}$ and week $12^{\text {th }}$. (c and d) Photomacrography of rat's brain of Dose 5 million week $8^{\text {th }}$ and week $12^{\text {th }}$. E and $F$ Photomacrography of rat's brain Dose 10 million week $8^{\text {th }}$ and week $12^{\text {th }}$. Scale $=5 \mathrm{~mm}$. Red lines limit the infarction areas. (b) Peri-infarction CD 31 Blood Vessel Expression. $C D 31$ is an angiogenesis marker. A positive signal was visualized by horseradish peroxidase 3,3-Diaminobenzidine (200x). A, B Control week $8^{\text {th }}$ and week $12^{\text {th }}$ C, D. Dose 5 million week $8^{\text {th }}$ and week $12^{\text {th }}$. E. F. Dose 10 million week $8^{\text {th }}$ and week $12^{\text {th }}$ (c). DCX expression and trend in neurogenesis. DCX positive cells are more prominent in the mononuclear cells group than the control group (400x)

\section{Interaction between the level of dose and length of treatment on neurogenesis}

An ANOVA two-way test was performed to assess the interaction between dose and time (week) and found a significant interaction between the size of dose and length of time on neurogenesis. A simple main effect test yielded the conclusion that enhancing dose from 5 million to 10 million BM-MNCs per $\mathrm{kg}$ BW had a 5.8 higher effect at week $12^{\text {th }}$ than at week $8^{\text {th }}(95 \%$ Confidence Interval -18.17441-29.77441, standard error 11.61608).

\section{The suggestive trend in neurogenesis from week $8^{\text {th }}$ to week $12^{\text {th }}$}

BM-MNCs administration showed suggestive different trends of neurogenesis for the two periods (Figure 3). An upward trend was apparent in the control groups and a downward was seen after the administration of BM-MNCs.

\section{Linear regression correlation between CD34, Behavior Test, and Histopathology findings}

The number of CD34+ cells contained in BM-MNC showed a linear correlation between the reduction in the infarct zone $(p=0.05)$ and improvement in neurogenesis $(p=0.04)$. Angiogenesis did not show a linear correlation with the CD34+ content.

\section{Discussion}

\section{Results of the cylinder test and NSS Scores after administration of BM-MNC}

This current study showed deficits in standard behavioral measures such as the cylinder test from the $1^{\text {st }}$ day following the MCAO procedure and the behavioral deficits reduced during the $1^{\text {st }}$ week after surgery. By the $14^{\text {th }}$ day following the procedure, it was barely possible to detect the deficits by use of the cylinder test. This might be explained by the spontaneous recovery of rats or there was rapid habituation due to frequent testing resulted in less tendency to rear and explore the plexiglass. This disadvantage was also commenced by Balkaya et al. (PMID 28760700) [10].

The markedly different NSS scores between groups at 4 weeks post-MCAO made this test unreliable as a means to interpret the outcome of BM-MNCs therapy in this study. However, since the NSS scores did not return to baseline after the $4^{\text {th }}$-week post-MCAO, this test is still considered reliable for evaluating the severity of stroke ischemia. In this study, after week $5^{\text {th }}$, the rats showed normal mNSS and this result was supported by the explanation which is (1) there was a spontaneous recovery and (2) in detecting behavioral deficits in the long-term study, NSS tends to be not useful [11], [12].

Both behavioral test results suggest that caution should be taken when selecting a simple behavioral test for detecting behavioral deficits in the chronic stage. 


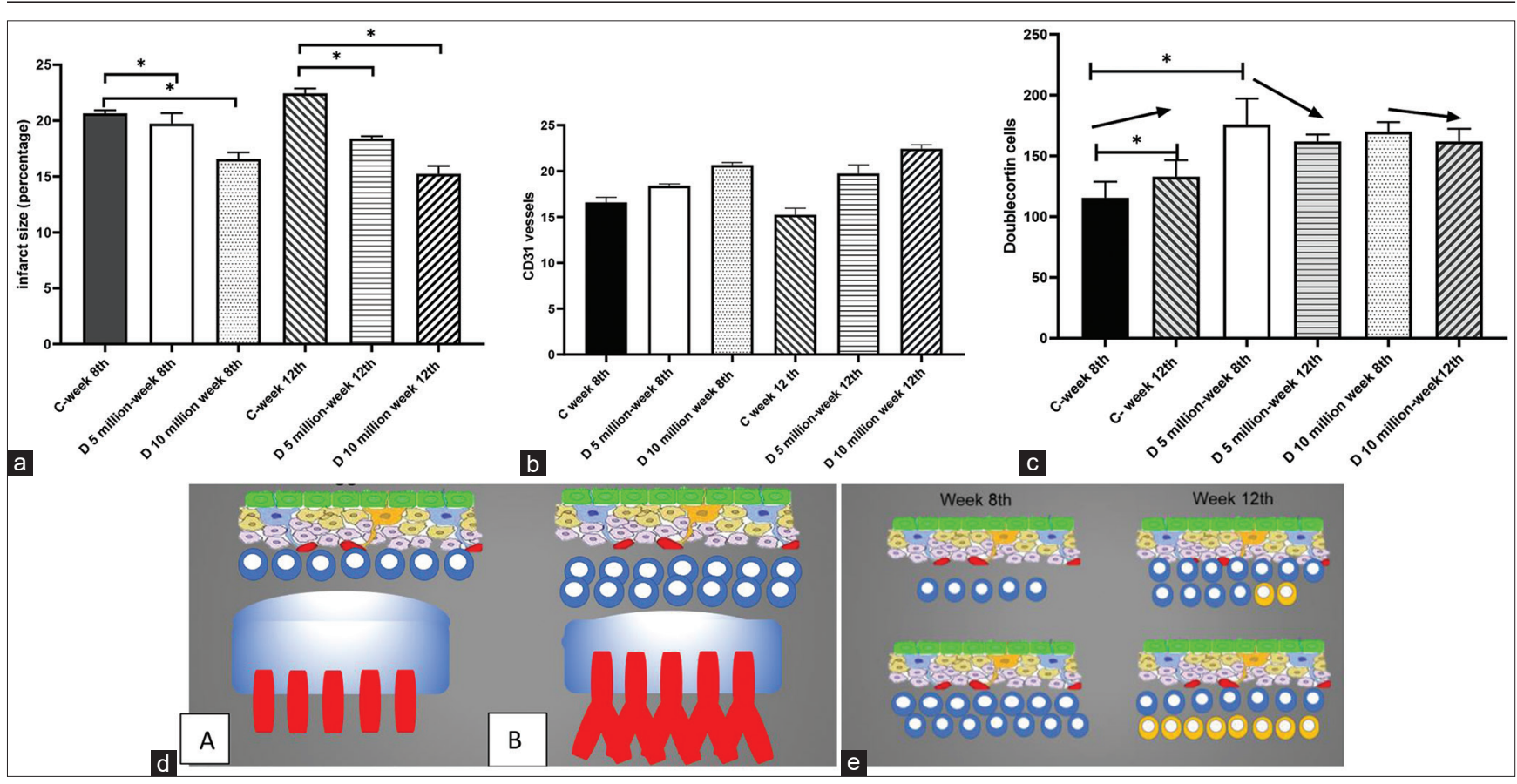

Figure 3: (a) Bar graph comparing infarction sizes between higher and lower doses and between week $8^{\text {th }}$ and week $12^{\text {th }}$. There were significant differences that were observed in infarction sizes $p<0.05, n=5$ in each group. The rats that had received 10 million cells of $\mathrm{kg} B W$ showed more reduction in infarction size than the lower dose. In the opposite site, control group showed an increase in infarction size. A graph is mean $\pm S D$. (b) Bar graph comparing of mean CD31 cells, the difference was not significant. (c) Mean of DCX (Doublecortin) positive cells in the subventricular zone. A graph is mean \pm SD. C-2. Mean of DCX positive cells at $8^{\text {th }}$ week and $12^{\text {th }}$ week $\left(^{*}=\right.$ significant, $\left.p<0.01\right)$. The black arrow means a change of neurogenesis trend. (d). Mononuclear Cells Reduce Infarct Zone, Improve Angiogenesis, and Neurogenesis A. Control group B. Mononuclear cells group. Bone marrow mononuclear cell (BM-MNCs) treatment after $4^{\text {th }}$-week middle cerebral artery occlusion decreases infarct zone, improve angiogenesis, and neurogenesis. Blue square means infarct area, red columns mean blood vessels, a round blue circle means neuroblasts. (e). Suggestive Change in The Trend of Neurogenesis from $8^{\text {th }}$ week to $12^{\text {th }}$ week (a). Saline treatment group (b) BM-MNCs treatment group. There was still an increase in the number of neuroblasts between those periods. In contrast, BM-MNCs treatment resulted in a decreasing number of neuroblasts and it appears that many have changed to mature neurons. A blue round shape is a neuroblast; the yellow round shape is a mature neuron

(BBB)

\section{$B M-M N C$ crosses the blood-brain barrier}

In this current study, BM-MNCs administered intracarotid at 4 weeks post-MCAO presumably cross the BBB; as a result, these cells are situated in the peri-infarction zone. This hypothesis is supported by Garbudoza-Davis et al. study which showed the significant damage of BBB, especially in the ipsilateral striatum and motor cortex in rats after 30 days MCAO. Their study also showed a separated microvascular change in the ipsilateral and contralateral brain areas, indicating the continuation of BBB damage in chronic ischemia [13].

Strbian et al. [14] evaluated leakage of BBB in rats post 90 min temporary MCAO ischemic-reperfusion using gadolinium (small molecules) and Evans Blue fluorescent (large molecules), demonstrated leakage for both within $25 \mathrm{~min}$ after reperfusion. They found that BBB remained open for 3 weeks for Evans Blue and 5 weeks for gadolinium, suggesting that there were would be permanent leakage of BBB in rats after ischemicreperfusion, without closing $B B B$ until the next few weeks [14].

Kamiya et al. [15] monitored the distribution of intra-arterial BM-MNC in rats using magnetic resonance imaging administered 90 min after MCAO. This study showed the distribution of BM-MNC in ischemic hemispheric $1 \mathrm{~h}$ after administration with a decrease in the number of cells by day- $7^{\text {th }}$ with the BM-MNC treatment group showing smaller infarct volume.

The fact that BM-MNC can enter brain circulation was shown by the Prabhakar et al. study in which BM-MNC was administered to mice intravenously, 24 $\mathrm{h}$ post-MCAO. This produced an accumulation of cells that were labeled with carboxyfluorescein diacetate in the infarct zone. This demonstrated that BM-MNC was not only able to cross BBB but also remained live for 1 week. However, the mechanism of BM-MNC crosses BBB is still uncertain [16].

There is a study that suggested mononuclear cells increased brain perfusion 1-15 min after injection through interaction with the host and release nitric oxide (NO). As a result, perfusion of the brain was increased and helped in entering brain circulation. NO inhibitor was administered in this study and they showed no improvement of neurological deficit in rats [17].

Our study administered ipsilateral intracarotid mononuclear cells at 4 weeks post-MCAO; however, we did not have any objective parameters to prove 
that BM-MNC entered the brain circulation. This is the limitation of our study. Nevertheless, improvement of infarct zone, neurogenesis, and angiogenesis, made us believe that BM-MNC works. Our route of administration is through ipsilateral intracarotid. BM-MNC presumably enters the open BBB in the area of the brain that has lots of fenestration, less permeable tight junction, especially around the cerebral intraventricle [18]. This might be the plausible explanation of the improvement of the infarct zone, angiogenesis, and neurogenesis that could be because of the effect of BM-MNC entered the brain circulation.

As this study did not label BM-MNCs that entered the brain's rats, other explanations of recovery of chronic stroke in this study, might be the paracrine effect of the BM-MNCs. This improvement in the chronic stage was supported by a study done in ten patients by Bhasin et al. [19], [20]. He demonstrated that the higher growth factors such as serum vascular endothelial growth factor (VEGF) and brain-derived neurotrophic growth factor (BDNF) were released in the BM-MNC group than the saline group. However, the difference was not significant. He hypothesized that due to the paracrine effect of stem cell niche and neurorehabilitation regime that released growth factors (VEGF and BDNF) in the microenvironment [19], [20].

\section{The mechanism by which BM-MNCs enhances recovery in the chronic stage}

Many papers have been written about recovery mechanism during the acute stage of ischemia, however, very limited paper discuss mechanism in the chronic phase. Our study demonstrated that BM-MNC transplantation improved recovery in angiogenesis (not significant), improved neurogenesis, and decreased the size of the infarct zone in the chronic stage of ischemic stroke. We also demonstrated that active neural proliferation was more obvious in the BM-MNC group in the subventricular zone than in the control group. The neural proliferation was not likely due to the ischemic injury itself because neural proliferation ended only until 2 weeks post-stroke in ischemia-induced condition [21], [22]. Instead of that, we administered BM-MNC 4 weeks post-MCAO. To show the neurogenesis process, we measured the number of immature neurons (DCX) in the subventricular zone in the week $8^{\text {th }}$ and week $12^{\text {th }}$. Thored et al. [23] labeled BrdU with DCX and suggested that DCX cells were immunoreactive over 2-3 week, but then gradually lost this expression and become marked with NeuN. Intriguingly, we demonstrated that there was still progression in the presence of neuroblast in the $8^{\text {th }}$ week and $12^{\text {th }}$ week, especially in the BM-MNC group treatment. However, we observed the different trends between control group and BM-MNC group. The downward trends of number of DCX cells in BM-MNC treatment group, suggested that many of the immature neurons (DCX cells) turn into the mature neurons and we hypothesized that BM-MNCs administration faster this neurogenesis process. This is the limitation of our study, so, the entire process of neurogenesis could be detailed explained (Figure 3). We suggest should measure the number of DCX neurons, mature neurons (Neu-N) in the penumbra and subventricular zone, to enhance the understanding of neurogenesis mechanism in the chronic stage.

The previous studies have shown that an increase in the number of new vessels in penumbra is correlated with improved outcomes in ischemic animal models. And angiogenesis occurs in 4-7 days after brain ischemia in the border of the ischemic core and periphery [24]. Similarly, we showed that in the week $8^{\text {th }}$ and week $12^{\text {th }}$ angiogenesis continued; however, the difference between the control group and experiment group was not significant. There appear to be several explanations for the enhancement of angiogenesis by BM-MNC: BM-MNC contains mesenchymal stem cells (MSCs) that are able to differentiate into smooth muscle and endothelial of vascular in MCAO rats; these differentiated cells ameliorate arteriogenesis (especially for leptomeningeal anastomosis) and angiogenesis; and MSCs might decrease the inflammatory response in the modulation of cytokine expression [25]. This is supported by Wang et al. study which showed that BM-MNC contains MMP-9 [26], this MMP-9 acts as a proteolytic enzyme that degrades the extracellular matrix in the glial scar [27], and increases neovascularization [28], neurogenesis, and synaptogenesis. MMP-9 also involves the migration of neuroprogenitors from the subventricular zone in ischemic stroke [29]. The role of neurogenesis of MMP-9 during the chronic stage was supported by Lee et al., [30] and inhibitors of MMPs were observed suppressing the migration of neurons from subventricular zone into the striatum [31]. However, the MMP-9 acts differently in acute stroke, which enhances leakage of BBB, resulted in more edema formation and hemorrhagic transformation [32].

The more detailed mechanism on angiogenesis of BM-MNC administration was observed by a study done by Kikuchi-Taura et al. [33]. Their study showed that BM-MNC administration; (1) increased the uptake of VEGF into endothelial cells and (2) able to bring glucose homolog to endothelial cells (PMID: 3207554).

The significant decreased in size of the infarct zone in the BM-MNC group is presumed to occur because those cells able to cross the BBB [17], stimulate angiogenesis, and neurogenesis (which is explained by the CD31 and DCX expression). Or it may be the paracrine effect that modulates an inflammation response, releases trophic factor, and cytokine that supports cito-protection [34], [35].

Besides all the mechanisms mentioned above, using freshly prepared cells in this study are such a huge advantage. Because it is clinically feasible, particularly in the chronic stage, and avoids problems related to cryopreservation. As a study done by Weise [36], administration of cryopreserved human 
umbilical cord blood mononuclear cells did not prove to induce sustained recovery after stroke in spontaneously hypertensive rats (PMID 24169850). The pursue of findings of cell treatment that is cost-effective and effective is the ultimate goal in countries with a shortage of cuttingedge cell preparation equipment and skills. In this current study, the procedure to process BM-MNC took only $2 \mathrm{~h}$ and the cost of each procedure was <200 USD.

\section{Recovery mechanism in the infarct focal chronic phase at week $8^{\text {th }}$ and week $12^{\text {th }}$}

Our study showed that the BM-MNC groups recovered markedly by week $12^{\text {th }}$, the explanation being that stimulation of angiogenesis and neurogenesis has reduced infarct size by week $12^{\text {th }}$. It also appears that BM-MNC therapy produces faster maturation of neurons in that period. This maturation trend was absent in the control group (Figure 3). The influence of angiogenesis follows a similar path to neurogenesis: BM-MNC enhances the neovascularization in the peri-infarct area. The maturation trend of a neuron is supported by Thored who observed that neuroblast is found at week 6 in the subventricular zone but that in week 16 more mature neurons were found than neuroblasts [37].

\section{Optimal dose in the recovery of functional neurology in the chronic phase focal infarct}

A higher dose (10 million cells per $\mathrm{kg} \mathrm{BW}$ ) of BM-MNC was found to be superior to the lower dose for improving the functional neurology deficit. This result was in accordance with the dose of MSCs of the "STem cell Application Researches and Trials In NeuroloGy" (STARTING) study (PMID 24083670) [38], $1 \times 10^{5}-3 \times 10^{6}$ cells/rat. Another study was done by Bhasin et al. [20] observed no functional outcomes difference between 10 million, 8 million, 7 million per kg BW BM-MNC in ten chronic stroke ischemia patients. Their study administered BM-MNCs intravenously. Our study administered ipsilateral intracarotid BM-MNCs. The difference site/route of administration also makes a significant difference in outcome results.

The reason for the higher dose showed more efficacies was partly that the higher number of mononuclear cells increases the potential to generate more progenitor cells. One of the cells was CD34+ cells. These hematopoietic stem cells were an important indicator of the success of BM-MNC therapy [39]. However, due to the small sample of CD34+ cells in this study, we cannot draw a direct conclusion on the effect of CD34+cells.

\section{Limitation of the study}

The key limitations of this study are the lack of an objective measure for the size of ischemia and that only two behavioral tests were applied. A further limitation was that only two biomarkers were used. The availability of detailed and comprehensive immunohistochemistry markers of neuron and synapse would enable a more comprehensive assessment of the recovery mechanism of chronic ischemic stroke in rats.

\section{Conclusion}

Doses of 10 million cells per kilogram of body weight were superior to doses of five 5 million cells per kilogram bodyweight in reducing infarct zone and improving angiogenesis and neurogenesis. The size of the dose did not produce significantly different behavioral measures on either the cylinder or NSS tests as there was already an improvement in the behavioral test measures before BM-MNC administration. Histopathological recovery was also observed to be greater at 12 weeks post-MCAO than at 8 weeks. We suggest performing behavioral assessment over a longer time frame and examination of other endpoints; such as genetics mechanism and synaptogenesis.

\section{Acknowledgments}

The author would like to thank Hetty Cislowski and his husband Noel Cislowski, Dr. Mery Ceria, Ms. Hilda, and everyone at the Animal Research Facilities in School of Medicine, Universitas Indonesia. The authors express special appreciation to Ms. Mely Kristanti for her kind support and assistance.

\section{Compliance with ethical standards}

(In case animals were involved) Ethical approval: All applicable international, national, and/or institutional guidelines for the care and use of animals were followed. All protocols were approved by the Animal Care and Use Committee of School of the Medicine University of Indonesia.

\section{References}

1. Brenneman M, Sharma S, Harting M, Strong R, Cox CS, Aronowski J, et al. Autologous bone marrow mononuclear cells enhance recovery after acute ischemic stroke in young and middle-aged rats. J Cereb Blood Flow Metab. 2010;30(1):1409. https://doi.org/10.1038/jcbfm.2009.198

PMid: 19773802 
2. Shen LH, Li Y, Chen J, Cui Y, Zhang C, Kapke A, et al. One-year follow-up after bone marrow stromal cell treatment in middleaged female rats with stroke. Stroke. 2007;38(7):2150-6. https:// doi.org/10.1161/strokeaha.106.481218

\section{PMid:17525391}

3. Koizumi J, Yoshida Y, Nakazawa T, Ooneda G. Experimental studies of ischemic brain edema, I: A new experimental model of cerebral embolism in rats in which recirculation can be introduced in the ischemic area. Jnp J Stroke. 1986;8:1-8.

4. Longa EZ, Weinstein PR, Carlson S, Cummins RJ. Reversible middle cerebral artery occlusion without craniectomy in rats. Stroke 1989;20:84-91. https://doi.org/10.1161/01.str.20.1.84 PMid:2643202

5. Makkiyah FA, Sadewo W. Technical report: Simple method of animal stroke model of luminal occlusion of middle cerebral artery in Indonesia. Surg Neurol Int. 2019;10(143):12-20. https:// doi.org/10.25259/sni_62_2019

PMid:31528478

6. Ordodi VL, Mic FA, Mic AA, Tanasie G, Ionac M, Sandesc D, et al. Bone marrow aspiration from rats: A minimally invasive procedure. Lab Anim. 2006;35(5):41-4. https://doi.org/10.1038/ laban0506-41

PMid:16645615

7. Serrano T, Pierozan P, Alberti E, Blanco L, de la Cuétara Bernal K, González ME, et al. Transplantation of mononuclear cells from bone marrow in a rat model of Huntington's disease. Journal of Neurorestoratology . 2016;4(1):95-106. https://doi. org/10.2147/jn.s118435

8. Liao SJ, Lin JW, Pei Z, Liu CL, Zeng JS, Huang RX. Enhanced angiogenesis with $\mathrm{dl}-3 \mathrm{n}$-butylphthalide treatment after focal cerebral ischemia in RHRSP. Brain Res. 2009;1289:69-78. https://doi.org/10.1016/j.brainres.2009.06.018

9. Hu X, Zheng H, Yan T, Pan S, Fang J, Jiang R, et al. Physical exercise induces expression of CD31 and facilitates neural function recovery in rats with focal cerebral infarction. J Neurol Res. 2010;32(4):397-402. https://doi.org/10.1179/0161641 $10 \times 12670144526309$

\section{PMid:20483007}

10. Balkaya MG, Trueman RC, Boltze J, Corbett D, Jolkkonen J. Behavioral outcome measures to improve experimental stroke research. Behav Brain Res 2018;352:161-71. https://doi. org/10.1016/j.bbr.2017.07.039

PMid:28760700

11. Trueman RC, Diaz C, Farr TD, Harrison DJ, Fuller A, Tokarczuk PF, et al. Systematic and detailed analysis of behavioural tests in the rat middle cerebral artery occlusion model of stroke: Tests for long-term assessment. J Cereb Blood Flow Metab. 2017;37(4):1349-61. https://doi. org/10.1177/0271678x16654921

PMid:27317655

12. Encarnacion $A$, Horie $\mathrm{N}$, Keren-Gill $\mathrm{H}$, Bliss $\mathrm{TM}$, Steinberg GK, Shamloo M. Long-term behavioral assessment of function in an experimental model for ischemic stroke. J Neurosci Methods. 2011;196(2):24757. https://doi.org/10.1016/j.jneumeth.2011.01.010 PMid:21256866

13. Garbuzova-Davis S, Haller E, Williams SN, Haim ED, Tajiri N, Hernandez-Ontiveros DG, et al. Compromised blood-brain barrier competence in remote brain areas in ischemic stroke rats at the chronic stage. J Comp Neurol. 2014;522(13):312037. https://doi.org/10.1002/cne.23582 PMid:24610730

14. Strbian D, Durukan A, Pitkonen M, Marinkovic I, Tatlisumak E, Pedrono $\mathrm{E}$, et al. The blood-brain barrier is continuously open for several weeks following transient focal cerebral ischemia. Neuroscience. 2008;153(1):175-81. https://doi.org/10.1016/j. neuroscience.2008.02.012

PMid: 18367342

15. Kamiya N, Ueda M, Igarashi $\mathrm{H}$, Nishiyama $\mathrm{Y}$, Suda S, Okubo S, et al. In vivo monitoring of arterially transplanted bone marrow mononuclear cells in a rat transient focal brain ischemia model using magnetic resonance imaging. J Neurol. 2013;35(6):573-9. https://doi.org/10.1179/1743132813y.0000000171

PMid:23561042

16. Prabhakar S, Muthaian R, Chabbra R, Anand A. Analysis of homing potential of marrow-derived mononuclear cells in an experimentally-induced brain stroke mouse model. J Brain Injury. 2010;24(12):1485-90. https://doi.org/10.3109/02699052. 2010.520298

PMid:20961175

17. Kasam M, Yang B, Strong R, Schaar K, Misra V, Xi X, et al. Nitric oxide facilitates delivery and mediates improved outcome of autologous bone marrow mononuclear cells in a rodent stroke model. PLoS One. 2012;7(3):e32793. https://doi.org/10.1371/ journal.pone. 0032793

PMid:22412926

18. Bombardi C, Grandis A, Chiocchetti R, Lucchi ML, Callegari E, Bortolami R. Membrane-transport systems in the fenestrated capillaries of the area postrema in rat and calf. J Anat Record. 2004;279(1):664-8. https://doi.org/10.1002/ar.a.20041 PMid:15224407

19. Bhasin A, Srivastava MP, Mohanty S, Bhatia R, Kumaran SS Bose S. Stem cell therapy: A clinical trial of stroke. Clin Neurol Neurosurg. 2013;115(7):1003-8. https://doi.org/10.1016/j. clineuro.2012.10.015

PMid:23183251

20. Bhasin A, Srivastava MP, Mohanty S, Vivekanandhan S, Sharma S, Kumaran S, et al. Paracrine mechanisms of intravenous bone marrow-derived mononuclear stem cells in chronic ischemic stroke. Cerebrovasc Dis Extra. 2016;6(3):10719. https://doi.org/10.1159/000446404 PMid:27846623

21. Arvidsson A, Kokaia Z, Lindvall O. N-methyl-D-aspartate receptor-mediated increase of neurogenesis in adult rat dentate gyrus following stroke. J Eur J Neurosci. 2001;14(1):10-8. https://doi.org/10.1046/j.0953-816x.2001.01611.x PMid:11488944

22. Yagita $\mathrm{Y}$, Kitagawa $\mathrm{K}$, Ohtsuki $\mathrm{T}$, Takasawa $\mathrm{KI}$, Miyata $\mathrm{T}$, Okano $\mathrm{H}$, et al. Neurogenesis by progenitor cells in the ischemic adult rat hippocampus. J Stroke. 2001;32(8):1890-6. https://doi. org/10.1161/01.str.32.8.1890

\section{PMid: 11486122}

23. Thored P, Wood J, Arvidsson A, Cammenga J, Kokaia Z, Lindvall $O$. Long-term neuroblast migration along blood vessels in an area with transient angiogenesis and increased vascularization after stroke. Stroke. 2007;38(11):3032-9. https:// doi.org/10.1161/strokeaha.107.488445

\section{PMid: 17901386}

24. Hatakeyama M, Ninomiya I, Kanazawa M. Angiogenesis and neuronal remodeling after ischemic stroke. J Neural Regen Res. 2020;15(1):16. https://doi.org/10.4103/1673-5374.264442 PMid:31535636

25. Huang P, Freeman WD, Edenfield BH, Brott TG, Meschia JF, Zubair AC. Safety and efficacy of intraventricular delivery of bone marrow-derived mesenchymal stem cells in hemorrhagic stroke model. Sci Rep. 2019;9(1):1-9. https://doi.org/10.1038/ s41598-019-42182-1

PMid:30952961

26. Wang G, Guo Q, Hossain M, Fazio V, Zeynalov E, Janigro D, et al. Bone marrow-derived cells are the major source of MMP-9 contributing to blood-brain barrier dysfunction 
and infarct formation after ischemic stroke in mice. Brain Res. 2009;1294:183-92. https://doi.org/10.1016/j. brainres.2009.07.070

PMid: 19646426

27. Cai $H, M a Y$, Jiang L, Mu Z, Jiang Z, Chen X, et al. Hypoxia response element-regulated MMP-9 promotes neurological recovery via glial scar degradation and angiogenesis in delayed stroke. Mol Ther. 2017;25(6):1448-59. https://doi.org/10.1016/j. ymthe.2017.03.020

PMid:28396199

28. Fitch MT, Silver J. CNS injury, glial scars, and inflammation: Inhibitory extracellular matrices and regeneration failure. J Exp Neurol. 2008;209(2):294-301. https://doi.org/10.1016/j. expneurol.2007.05.014

PMid: 17617407

29. Wang L, Zhang ZG, Zhang RL, Gregg SR, Hozeska-Solgot A, LeTourneau Y, etal. Matrix metalloproteinase 2(MMP2)and MMP9 secreted by erythropoietin-activated endothelial cells promote neural progenitor cell migration. J Neurosci. 2006;26(22):59966003. https://doi.org/10.1523/jneurosci.5380-05.2006 PMid: 16738242

30. Lee SR, Kim HY, Rogowska J, Zhao BQ, Bhide P, Parent JM, et al. Involvement of matrix metalloproteinase in neuroblast cell migration from the subventricular zone after stroke. J Neurosci. 2006;26(13):3491-5. https://doi.org/10.1523/ jneurosci.4085-05.2006

PMid: 16571756

31. Zhao BQ, Tejima E, Lo E. Neurovascular proteases in brain injury, hemorrhage and remodeling after stroke. Stroke. 2007;38(2):748-52. https://doi.org/10.1161/01. str.0000253500.32979.d1

PMid: 17261731

32. Rosell A, Ortega-Aznar A, Alvarez-Sabín J, FernándezCadenas I, Ribó M, Molina CA, et al. Increased brain expression of matrix metalloproteinase- 9 after ischemic and hemorrhagic human stroke. Stroke. 2006;37(6):1399-406. https://doi. org/10.1161/01.str.0000223001.06264.af PMid:16690896

33. Kikuchi-Taura A, Okinaka $\mathrm{Y}$, Takeuchi $\mathrm{Y}$, Ogawa $\mathrm{Y}$, Maeda $\mathrm{M}$, Kataoka $Y$, et al. Bone marrow mononuclear cells activate angiogenesis via gap junction-mediated cell-cell interaction. Stroke. 2020;51(4):1279-89. https://doi.org/10.1161/ strokeaha. 119.028072

PMid:32075549

34. Giraldi-Guimarães A, Rezende-Lima M, Bruno FP, MendezOtero R. Treatment with bone marrow mononuclear cells induces functional recovery and decreases neurodegeneration after sensorimotor cortical ischemia in rats. Brain Res. 2009;1266:10820. https://doi.org/10.1016/j.brainres.2009.01.062 PMid: 19368806

35. lihoshi S, Honmou O, Houkin K, Hashi K, Kocsis JD. A therapeutic window for intravenous administration of autologous bone marrow after cerebral ischemia in adult rats. Brain Res. 2004;1007(1):1-9. https://doi.org/10.1016/j. brainres.2003.09.084

PMid: 15064130

36. Weise G, Lorenz M, Pösel C, Riegelsberger UM, Störbeck V, Kamprad $\mathrm{M}$, et al. Transplantation of cryopreserved human umbilical cord blood mononuclear cells does not induce sustained recovery after experimental stroke in spontaneously hypertensive rats. J Cereb Blood Flow Metab. 2014;34(1):e1-9. https://doi.org/10.1038/jcbfm.2013.185 PMid:24169850

37. Thored P, Arvidsson A, Cacci E, Ahlenius H, Kallur T, Darsalia V, et al. Persistent production of neurons from adult brain stem cells during recovery after stroke. Stem Cells. 2006;24(3):73947. https://doi.org/10.1634/stemcells.2005-0281 PMid:16210404

38. Kim SJ, Moon GJ, Chang WH, Kim YH, Bang OY. Intravenous transplantation of mesenchymal stem cells preconditioned with early phase stroke serum: current evidence and study protocol for a randomized trial. Trials 2013;14(1):317. https:// doi.org/10.1186/1745-6215-14-317

PMid:24083670

39. Yasuhara S, Yasunaga $Y$, Hisatome T, Ishikawa M, Yamasaki T, Tabata $Y$, et al. Efficacy of bone marrow mononuclear cells to promote bone regeneration compared with isolated $\mathrm{CD}_{34}+$ cells from the same volume of aspirate. Artif Organs. 2010;34(7):5949. https://doi.org/10.1111/j.1525-1594.2009.00980.x PMid:20528851 